\title{
Controvérsias sociocientíficas: análise comparativa entre Brasil e Portugal
}

Socioscientific issues: comparative analysis between Brazil and Portugal

\author{
Carla Krupczak ${ }^{1}$ \\ Joanez Aparecida Aires ${ }^{2}$ \\ Pedro Guilherme Rocha dos Reis ${ }^{3}$
}

\section{Resumo}

A discussão de controvérsias sociocientíficas é uma das estratégias didáticas que podem estimular o desenvolvimento da alfabetização científica. Mas, essa abordagem é utilizada da mesma forma e com os mesmos objetivos em diferentes contextos educacionais? Pensando nisto, este trabalho tem como objetivo analisar como as controvérsias sociocientíficas são abordadas nas pesquisas brasileiras e portuguesas, buscando identificar as semelhanças e diferenças dos dois contextos educacionais e de pesquisa. Os dados foram constituídos no Brasil e em Portugal, a partir do Catálogo de Teses e Dissertações da CAPES e do site do repositório do Instituto de Educação da Universidade de Lisboa, respectivamente. Os resultados mostram que os pesquisadores portugueses usam a discussão de controvérsias sociocientíficas, sobretudo, para desenvolver competências para a cidadania e ativismo. Já as investigações brasileiras têm como objetivo, principalmente, a aprendizagem dos conteúdos científicos. Isto pode estar relacionado com a menor qualidade da educação básica brasileira, por vários motivos, que vão desde as lacunas na formação dos professores até a pouca valorização da profissão docente.

Palavras-chave: questões sociocientíficas; pesquisas brasileiras; pesquisas portuguesas.

\section{Abstract}

The discussion of socioscientific issues is one of the didactic strategies that can stimulate the development of scientific literacy. But, is this approach used in the same way and with the same goals in different educational contexts? With this in mind, this paper aims to analyze how socioscientific issues are addressed in Brazilian and Portuguese research, seeking to identify the similarities and differences of the two educational and research contexts. The data was compiled in Brazil and Portugal, starting from the CAPES Thesis and Dissertations Catalog and from the repository website of the Education Institute of the University of Lisbon, respectively. The results show that Portuguese researchers use the discussion of socioscientific issues, mainly to develop skills for citizenship and activism. Brazilian investigations, on the other hand, aim mainly at learning scientific content. This may be related to the lower quality of basic education in Brazil, for several reasons, ranging from gaps in teacher training to the low valuation of the teaching profession.

Keywords: socioscientific issues; Brazilian researches; Portuguese researches.

\footnotetext{
${ }^{1}$ Universidade Federal do Paraná | carlak.quim@gmail.com

${ }^{2}$ Universidade Federal do Paraná | joanez.ufpr@gmail.com

${ }^{3}$ Universidade de Lisboa | preis@ie.ulisboa.pt
} 


\section{Introdução}

Uma pesquisa realizada recentemente pelo Centro de Gestão e Estudos Estratégicos (CGEE) mostrou que 62\% dos brasileiros têm algum interesse em temas relacionados à ciência e tecnologia. No entanto, grande parte desconhece conceitos científicos básicos. Por exemplo, 73\% dos entrevistados acreditam que antibióticos matam vírus (CGEE, 2019). A falta de conhecimentos mostra-se grave, principalmente, em momentos de crise, como a que acontece no mundo todo em 2020 relacionada a Covid-19. Apesar da pouca compreensão dos conteúdos científicos, 83,3\% dos participantes da pesquisa defendem que a população deveria participar da tomada de decisões em assuntos que envolvem ciência e tecnologia. E mais de $80 \%$ das pessoas se dizem preocupadas com o desmatamento da Amazônia, os danos ambientais causados pela mineração, o uso de agrotóxicos na agricultura e os efeitos das mudanças climáticas (CGEE, 2019). Todos estes assuntos citados são chamados de controvérsias sociocientíficas (CSC).

As CSC são situações de cunho científico e tecnológico, frequentes nos meios de comunicação, que se relacionam com a sociedade, causando disputas entre diferentes grupos sociais (KOLSTO, 2001). Elas são complexas e podem ser entendidas e resolvidas de diversas formas. Como explicitado, são assuntos que chamam a atenção da população, mas que exigem um mínimo de conhecimento científico para serem entendidas. Nesse sentido, o ensino de ciências revela-se determinante na formação de cidadãos conscientes e preparados para tomar decisões. Ou seja, a sociedade necessita de pessoas alfabetizadas cientificamente. Pensando nisso, a literatura da área educacional apresenta diferentes abordagens didáticas que podem desenvolver a alfabetização científica. Uma destas é a discussão de CSC nas aulas de ciências (KRUPCZAK; LORENZETTI; AIRES, 2020).

Tendo por base tais argumentos, esta investigação tem como objetivo analisar como as CSC são abordadas nas pesquisas brasileiras e portuguesas, buscando identificar as semelhanças e diferenças dos dois contextos educacionais e de pesquisa. Consideramos que conhecer as abordagens de tais contextos pode abrir horizontes, no sentido de uma melhor compreensão sobre como as CSC podem ser usadas nas aulas de ciências para fomentar a alfabetização científica ${ }^{4}$.

\section{Controvérsias sociocientíficas na educação científica}

A ciência, apesar de baseada na racionalidade, gera algumas controvérsias. Estas podem ser científicas ou sociocientíficas ${ }^{5}$. A primeira corresponde a disputas acadêmicas entre grupos de cientistas sobre teorias e explicações diversas para um mesmo fenômeno.

\footnotetext{
4 Entendemos, assim como Hurd (1998, p. 410, tradução nossa), que "a alfabetização científica é vista como uma competência cívica exigida para o pensamento racional sobre a ciência em relação a problemas pessoais, sociais, políticos, econômicos e questões que provavelmente ocorrerão ao longo da vida".

${ }^{5} \mathrm{Na}$ literatura inglesa são chamadas de socioscientific issues. Em português foram traduzidas como controvérsias sociocientíficas, questões sociocientíficas, assuntos controversos, temas controversos ou aspectos sociocientíficos. No entanto, todos estes termos são usados para o mesmo tipo de problemas científicos que envolvem questões sociais, ambientais, econômicas, morais, éticas, políticas, entre outros. Neste artigo, optamos pela expressão 'controvérsias sociocientíficas', porque defendemos que esta representa melhor o caráter controverso e científico/social das referidas situações.
} 
A segunda envolve questões sociais, morais, econômicas, políticas, religiosas, éticas, culturais, entre outras, que podem ocorrer na esfera mais ampla da sociedade, fora dos grupos de cientistas (REIS, 2009).

Hilário e Reis (2009, p. 169) afirmam que "as controvérsias sociocientíficas representam uma diversidade de dilemas sociais resultantes da aplicação dos princípios e práticas científicas e tecnológicas". Kolsto (2001) declara que as controvérsias sociocientíficas (CSC) são comumente abordadas pelos meios de comunicação e são avaliadas de formas diferentes por grupos sociais com interesses variados. Zeidler e Nichols (2009) acrescentam que as CSC envolvem raciocínio moral e ético no processo de tomada de decisões. Portanto,

As controvérsias sociocientíficas descrevem os dilemas da sociedade com vínculos conceituais, processuais ou tecnológicos à ciência. Muitas controvérsias sociocientíficas decorrem de dilemas envolvendo biotecnologia, problemas ambientais e genética humana. [...] os tópicos descritos pelo termo 'controvérsias sociocientíficas' exibem um grau único de interesse social, efeito e consequência. As controvérsias sociocientíficas são tipicamente contenciosas por natureza, podem ser consideradas a partir de uma variedade de perspectivas, não possuem conclusões simples e frequentemente envolvem moralidade e ética (SADLER; ZEIDLER, 2004, p. 5, tradução nossa).

As CSC podem surgir porque uma tecnologia ou teoria pode causar tensões sociais, com mudanças no investimento público, em direitos individuais, em interesses econômicos, nas prioridades políticas, nas preocupações ambientais, em questões morais ou éticas, entre outros. Para uma questão ser considerada controversa, ela precisa envolver interesses opostos e ter diferentes soluções por grupos sociais variados (ESPÍRITO SANTO; REIS, 2013).

São exemplos de CSC: produção de alimentos transgênicos, uso de células-tronco, aquecimento global, uso de agrotóxicos, clonagem de seres vivos, energia nuclear, biocombustíveis, a instalação de empresas multinacionais, aborto, mudanças climáticas, manipulação genética, entre outros. Segundo Sadler (2004), as CSC podem ser regionais, quando afetam apenas uma determinada comunidade, ou globais, quando são comuns em todo o mundo. O primeiro tipo é mais interessante para os alunos, pois afeta sua vida diretamente, o que aproxima a ciência da realidade do estudante. É importante discutir CSC globais, como mudanças climáticas ou aborto, mas questões regionais podem ser mais fáceis de entender ou discutir e, na maioria dos casos, geram intervenções mais frutíferas.

A discussão sobre CSC tem potencial para estimular o desenvolvimento de habilidades cognitivas e sociais, como: trabalho cooperativo, argumentação, pesquisa de informações, pensamento crítico, tomada de decisões, construção de hipóteses, saber escutar opiniões diferentes, entre outras (KOLSTO, 2001; SADLER; ZEIDLER, 2004; HILÁRIO; REIS, 2009; ZEIDLER; NICHOLS, 2009; ESPÍRITO SANTO; REIS, 2013; SCHEID; REIS, 2016; FANICA, 2017; COSTA, 2018; ALMEIDA; GUIMARÃES, 2019). Além disso, a discussão de CSC torna os alunos mais participativos e autônomos, o que facilita a aprendizagem de todos os conteúdos. Os estudantes também adquirem maior consciência social, tornando-se cidadãos ativos e capazes de formular opiniões e tomar decisões na sociedade (ESPÍRITO SANTO; REIS, 2013).

De acordo com Zeidler e Nichols (2009), no meio das discussões o raciocínio de um aluno influencia ou produz reflexão no outro, pois eles conhecem diferentes opiniões e experiências. Os estudantes são obrigados a negociar e resolver os conflitos, melhorando 
seus argumentos. Além disso, aprendem a respeitar e ouvir compreensões de mundo diferentes e minoritárias. Hilário e Reis (2009) acrescentam que, em momentos de discussão de CSC, diferentes grupos usam argumentos diversos. Alguns utilizam mais alegações éticas e morais, outros políticas e econômicas, outros científicas e técnicas, dependendo da origem e conhecimento de cada grupo.

Zeidler e Nichols (2009) lembram que os interesses dos estudantes são diferentes dos objetivos da escola. Dificilmente os educandos pensam em divisão celular, ligação química ou difração da luz. Eles refletem sobre sua realidade, sobre os acontecimentos da sua vida e como isso os afeta. Portanto, as CSC são uma forma de aproximar os conteúdos científicos da realidade dos alunos, tornando a ciência mais atrativa e interessante.

Além disso, Karisan e Zeidler (2017) afirmam que a discussão de CSC pode ser usada como contexto para a compreensão da natureza da ciência ${ }^{6}$. Assuntos controversos evidenciam os aspectos da construção do conhecimento científico, ajudando os alunos a tomar decisões sobre questões complexas. Estes autores afirmam, ainda, que "não apenas o entendimento de um indivíduo sobre a natureza da ciência altera inevitavelmente a maneira como ele responde a situações envolvendo ciência, incluindo controvérsias sociocientíficas, mas também contextos de CSC alteram a forma como os alunos respondem/entendem a natureza da ciência" (KARISAN e ZEIDLER, 2017, p. 147, tradução nossa).

Hilário e Reis (2009) realizaram uma atividade de discussão de CSC com turmas do $12^{\circ}$ ano de uma escola portuguesa e concluíram que:

\begin{abstract}
A discussão das controvérsias sociocientíficas permitiu o acesso dos alunos a uma perspectiva da ciência distinta da que Ihes é transmitida durante a maior parte das aulas de ciências - uma ciência objetiva, livre de valores e de influências. Através das atividades de discussão, a ciência surge-lhes como um campo onde nem sempre as soluções são únicas e que estabelece interações diversas com a sociedade. $O$ facto das situações em análise se situarem na chamada 'ciência de fronteira', a qual se caracteriza por se constituir a partir de descobertas recentes e divergentes, para as quais não há consenso entre a comunidade científica [...] permitiu aos alunos uma visão da ciência diferente daquela a que estavam habituados (HILÁRIO; REIS, 2009, p. 180).
\end{abstract}

Um exemplo de como uma CSC pode fazer os alunos refletirem sobre a natureza da ciência é descrito por Lederman, Antink e Bartos (2014). Os autores usam o tema alimentos transgênicos para demonstrar como fatores culturais e políticos afetam a interpretação que as pessoas fazem de um mesmo assunto. Na Europa as normas para transgênicos são rígidas, sendo obrigatória a rotulagem de comidas contendo tais produtos. Já nos Estados Unidos, as regras são mais brandas e a indicação destes alimentos nos rótulos não é obrigatória. Dessa forma, a população europeia é mais informada e tem maior consciência do quanto os transgênicos estão presentes em sua dieta, quando comparados com os estadunidenses. Por isso, europeus são mais contrários a este tipo de produto do que os

\footnotetext{
${ }^{6}$ Adotamos aqui a definição de natureza da ciência de Moura (2014, p. 33): "De uma perspectiva bem ampla e geral, podemos dizer que a natureza da ciência envolve um arcabouço de saberes sobre as bases epistemológicas, filosóficas, históricas e culturais da ciência. Compreender a natureza da ciência significa saber do que ela é feita, como elaborá-la, o que e por que ela influencia e é influenciada".
} 
norte-americanos. Este exemplo mostra as relações socioculturais que as pessoas têm com a ciência e tecnologia. Apesar dos dados científicos sobre transgênicos serem os mesmos em todo o mundo, diferentes populações se relacionam de forma diversa com eles. Logo, este exemplo evidencia como a ciência é afetada pela sociedade e vice e versa, explicitando a não neutralidade científica. Portanto, as CSC são uma forma de abordar aspectos da natureza da ciência.

Em termos práticos, Hilário e Reis (2009) relatam os fatores que afetam a discussão de CSC, com base em uma pesquisa realizada por eles. Uma destas condições é o tema, o qual quanto mais próximo da realidade do aluno, melhores serão as discussões. Também influencia a compreensão de conceitos científicos, quanto maior o conhecimento dos participantes da conversa, mais facilmente as decisões são tomadas.

Outro ponto importante das atividades envolvendo CSC é o professor. O docente precisa agir como um facilitador. Ele deve organizar e estimular a discussão, mas o centro de todo o processo deve ser o estudante. É importante que o educador dê voz aos alunos, de modo que eles desenvolvam sua autonomia e expressem suas opiniões, de forma igualitária entre todos. O professor deve evitar expor suas ideias para que os educandos não pensem que existe uma resposta correta para o problema (ZEIDLER; NICHOLS, 2009).

Zeidler e Nichols (2009) alertam que, ao desenvolver atividades relacionadas com CSC, os professores devem buscar as informações com antecedência, para garantir que os alunos sejam confrontados com diferentes perspectivas. Podem ser usados como fonte de informação: internet, jornais, revistas, livros, fotografias, programas de televisão, artigos, entre outros. Sadler (2004) aponta que as pessoas têm muita dificuldade em avaliar as fontes de informação. Muitas vezes, isso é feito apenas com base no valor aparente e em critérios superficiais. Portanto, avaliar a confiabilidade das informações é parte importante da discussão de CSC e deve ser estimulada pelo professor. Afinal,

Confrontados com as vastas correntes de informação na sociedade moderna, é vital que os estudantes sejam treinados para olhar todas as afirmações que encontram em uma luz crítica. Em uma democracia, isso é sempre importante. Queremos que as opiniões sejam formadas e as decisões tomadas na melhor base possível. Portanto, é importante que tanto os cientistas em potencial quanto os leigos sejam treinados em argumentação e desenvolvam uma atitude crítica em relação à informação, às reivindicações de conhecimento e às linhas de argumentação (KOLSTO, 2001, p. 304, tradução nossa).

Um exemplo prático do uso das CSC no ensino para desenvolvimento das habilidades descritas até aqui é o projeto português We Act:

O principal objetivo do projeto 'We Act' é o desenvolvimento, uso e estudo de materiais e metodologias destinadas a apoiar/assessorar professores e alunos (da escola primária à universidade) na realização de ações informadas e negociadas sobre problemas sociais e ambientais associados aos campos de ciência e tecnologia (também conhecidos como controvérsias em ciência, tecnologia, sociedade e meio ambiente CCTSA - ou controvérsias sociocientíficas - CSC). [...] O projeto combina componentes de desenvolvimento, ação e pesquisa e cruza três áreas diferentes: a) a promoção do aprendizado com base em pesquisas ativas sobre controvérsias da vida real relacionadas à ciência e tecnologia; b) incentivo à participação dos estudantes em ações democráticas e coletivas 
de solução de problemas; c) apoiar as duas primeiras áreas com iniciativas artísticas [...] e o uso de ferramentas da Web 2.0 (REIS, 2014, p. 18-19, tradução nossa).

Os professores que participaram do projeto perceberam que as atividades de discussão de CSC e de ação sociopolítica desencadeadas, desenvolveram competências para a cidadania em todos os envolvidos (alunos e docentes). Eles conseguiram compreender melhor as relações entre a ciência, a tecnologia e a sociedade e puderam criar mudanças em suas aulas, escolas e sociedades. Além disso, os docentes construíram uma rede de apoio, em que podem compartilhar êxitos e fracassos e combater os sentimentos de desânimo (REIS, 2014).

Portanto, as pesquisas indicam que a discussão de CSC é uma forma de desenvolver a alfabetização científica dos estudantes, visto que facilita a compreensão dos conteúdos científicos, da natureza da ciência e das relações ciência, tecnologia e sociedade (KOLSTO, 2001; HILÁRIO; REIS, 2009; ZEIDLER; NICHOLS, 2009; ESPÍRITO SANTO; REIS, 2013; COSTA, 2018; LEITE; RODRIGUES, 2018; KRUPCZAK; LORENZETTI; AIRES, 2020). Além disso, ajuda na formação de cidadãos ativos e participativos, que contribuem com a tomada de decisões na sociedade, pois

[...] a posse de profundos conhecimentos específicos, como os que possuem os especialistas num campo determinado de saber, não garante a adoção de decisões adequadas, mas exigem enfoques que contemplem os problemas numa perspectiva mais ampla, analisando as possíveis repercussões a médio e longo prazo, tanto no campo considerado como em outros campos (PRAIA; PÉREZ; VILCHES, 2007, p. 143, grifo dos autores).

Ou seja, não são apenas os especialistas que devem se envolver na tomada de decisões. A população geral, desde que tenha conhecimento científico mínimo sobre o problema em questão, pode participar do processo, contribuindo com opiniões fundamentadas.

\section{Metodologia}

Esta investigação é qualitativa e do tipo estado do conhecimento. É qualitativa, porque os dados são principalmente descritivos e o foco da análise é o significado que as pessoas dão às situações e objetos (LUDKE; ANDRÉ, 2013). É do tipo estado do conhecimento, porque estas são pesquisas que buscam a produção acadêmica em um segmento específico, neste caso teses e dissertações, com o objetivo de entender como determinado assunto está se desenvolvendo em uma área do conhecimento (ROMANOWSKl; ENS, 2006).

A constituição dos dados referentes ao Brasil foi feita no Catálogo de Teses e Dissertações da Capes em fevereiro de 2019. Os termos de busca utilizados foram: controvérsias sociocientíficas, questões sociocientíficas, assuntos controversos, tema controverso e aspecto sociocientífico (todos no singular e plural). Buscaram-se os trabalhos defendidos até 2017, que fossem de Programas de Pós-graduação das áreas de Educação e Ensino. Os resumos dos trabalhos foram lidos para confirmar se os mesmos realmente tinham como escopo as CSC. Dessa forma, foram selecionadas 49 dissertações e 20 teses brasileiras. 
Os dados relativos a Portugal foram constituídos no site do repositório do Instituto de Educação da Universidade de Lisboa em janeiro de 2020. Os termos de busca usados foram os mesmos dos trabalhos brasileiros. Foram selecionados os trabalhos defendidos até 2019, que indicavam no resumo ter como alvo as CSC. Assim, foram encontradas 18 dissertações e 6 teses portuguesas.

Os dados foram analisados usando-se sete descritores definidos a priori: 1) ano de defesa; 2) grau de titulação; 3) palavras-chave; 4) nível de ensino; 5) tipo de (SC; 6) foco temático; 7) natureza da ciência. Adiante, os descritores e resultados são explicados.

\section{Resultados e discussão}

A quantidade de trabalhos portugueses e brasileiros por ano de defesa e grau de titulação encontra-se na Figura 1. A produção do país americano é maior, uma vez que o número de universidades é superior. No entanto, a distribuição temporal é próxima. Apesar da existência de algumas investigações em anos anteriores, as pesquisas concentram-se entre 2010 e 2017. Além disso, nos dois casos a grande maioria dos trabalhos é de mestrado.

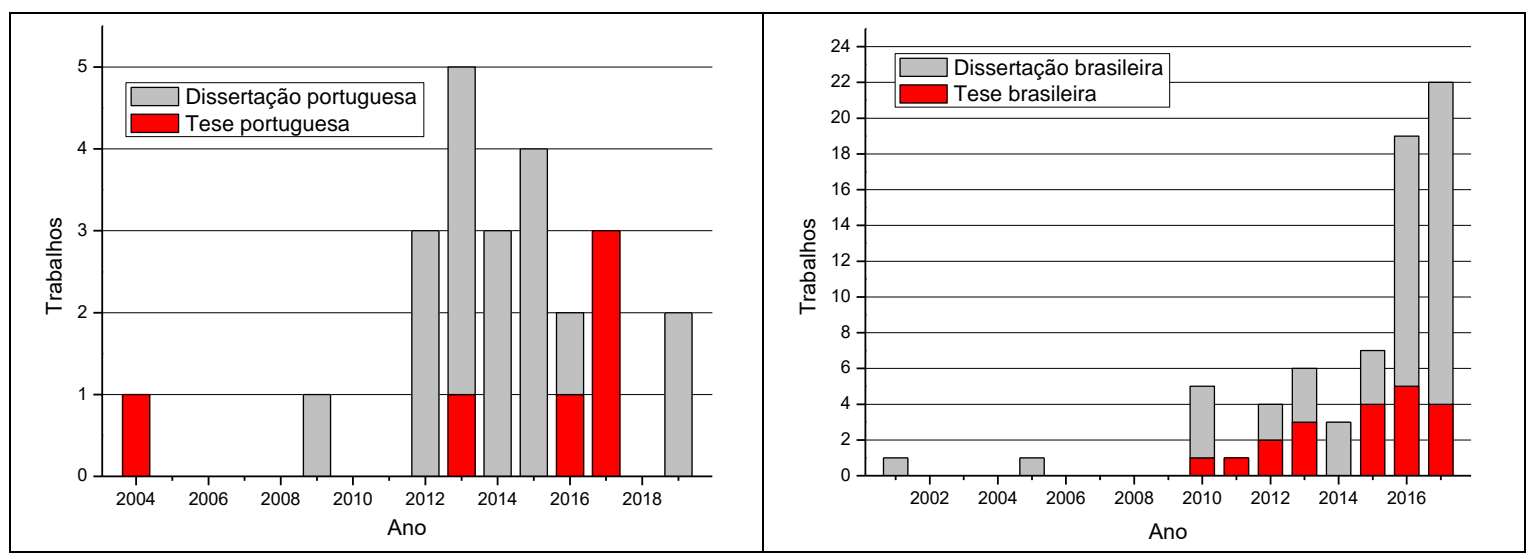

Figura 1: Quantidade de trabalhos portugueses e brasileiros por ano e grau de titulação.

As seis palavras-chave mais frequentes nas teses e dissertações brasileiras e portuguesas encontram-se no Quadro 1. A palavra mais comum, nos dois países, como esperado, está relacionada com as CSC, uma vez que correspondem ao tema das pesquisas. No entanto, é interessante notar que no Brasil existe uma diversidade maior de termos para referir-se às CSC. A segunda palavra-chave mais frequente nas investigações dos dois países está relacionada com a área em que as pesquisas são realizadas (Educação em Ciências, Ensino de Ciências ou Educação Científica) é, portanto, um termo genérico frequente em trabalhos dessa área.

Uma correspondência entre as pesquisas está nos termos 'alfabetização científica' e 'literacia científica' (que são expressões diferentes para referir-se ao mesmo objetivo). Como já discutimos, a alfabetização científica pode ser estimulada pela discussão de CSC e é considerada um dos objetivos da Educação Científica em vários países há muitos anos (REIS, 1997; HURD, 1998; AULER; DELIZOICOV, 2001; HOLBROOK; RANNIKMAE, 2009; SASSERON; CARVALHO, 2011; LOPES; GARCIA, 2019). Logo, está presente em pesquisas realizadas em diferentes contextos educacionais, sendo comum ao Brasil e a Portugal. Outra semelhança 
entre os trabalhos está nos termos 'argumentação' e 'desenvolvimento de competências', pois o primeiro faz parte do segundo:

[...] é essencial que se promovam práticas de sala de aula que desenvolvam competências diversas, como a argumentação, Dessa forma, o sistema educativo estará a contribuir para desenvolver nos cidadãos a capacidade de avaliação crítica, através da análise de diferentes argumentos apresentados em relação a questões científicas controversas, permitindo-lhes tomar posições de uma forma democrática, responsável e cientificamente sustentada. Consideramos que a implementação de práticas de trabalho colaborativo envolvendo, nomeadamente, a interacção entre pares, em sala de aula, poderá ser um contributo importante para o desenvolvimento deste tipo de competências (ALMEIDA; CÉSAR, 2007, p. 163).

Quadro 1: Palavras-chave mais frequentes nas teses e dissertações brasileiras e portuguesas.

\begin{tabular}{|c|c|c|}
\hline $\begin{array}{c}\text { Ordem de } \\
\text { frequência }\end{array}$ & $\begin{array}{c}\text { Teses e dissertações } \\
\text { portuguesas }\end{array}$ & Teses e dissertações brasileiras \\
\hline $1^{\text {a }}$ & $\begin{array}{c}\text { Controvérsias sociocientíficas ou } \\
\text { questões sociocientíficas }\end{array}$ & $\begin{array}{c}\text { Questões sociocientíficas ou controvérsias } \\
\text { sociocientíficas ou aspectos sociocientíficos ou } \\
\text { temas controversos ou tema sociocientífico }\end{array}$ \\
\hline $2^{a}$ & $\begin{array}{c}\text { Educação em Ciências ou Ensino } \\
\text { de Ciências }\end{array}$ & $\begin{array}{r}\text { Educação em Ciências ou Ensino de Ciências } \\
\text { ou Educação Científica }\end{array}$ \\
\hline $3^{a}$ & Ativismo & Educação ou movimento CTS ou CTSA \\
\hline $4^{a}$ & Literacia científica & Formação de professores \\
\hline $5^{a}$ & Desenvolvimento de \\
competências & Alfab̧ão \\
\hline $6^{a}$ & Cidadania & \\
\hline
\end{tabular}

Portanto, tanto pesquisadores brasileiros, quanto portugueses, entendem que as CSC podem ser utilizadas para desenvolver competências importantes, como a argumentação e, ainda, exploram tal potencialidade, como indica a presença destes termos nas palavraschave.

As diferenças entre as pesquisas brasileiras e portuguesas podem ser notadas pelas outras palavras-chave. No Brasil, grande parte das investigações tem como foco a formação de professores. Isso indica que a temática ainda não é muito conhecida no país, o que já foi indicado na literatura (KRUPCZAK; AIRES, 2019). Afinal, quando uma temática ou metodologia é recente na área educacional, é preciso investir na formação de professores para que esta, primeiramente seja compreendida, para então passar a incorporar as atividades didáticas nas salas de aula. Pois, "[...] cabe aos professores estabelecer a ponte entre a cultura associada à comunidade de cientistas e o resto da sociedade através da iniciação dos alunos em determinados aspectos da cultura científica" (GALVÃO; REIS; FREIRE, 2011, p. 508).

Também se percebe que no Brasil as CSC são abordadas tendo por base a Educação CTS ou CTSA, ou seja, as CSC são usadas como forma de evidenciar as relações que existem 
entre a ciência, a tecnologia, a sociedade e o ambiente. No entanto, Zeidler e Nichols (2009) alertam que, apesar dos objetivos da Educação CTS e da discussão sobre temas controversos serem parecidos, as CSC são mais abrangente. Porque estas enfocam, além das relações CTS, aspectos da NDC e itens éticos e morais.

Já em Portugal o foco das pesquisas está no ativismo e na cidadania. Uma parte dessas pesquisas está vinculada ao projeto 'We Act', que visa subsidiar professores e alunos na realização de ações sociopolíticas informadas (SCHEID; REIS, 2016; REIS; TINOCA, 2018). Fanica (2017) argumenta que, se os professores levam CSC atuais e relacionadas com a realidade dos estudantes para as aulas e os incentivam a refletir sobre elas,

[...] os alunos percepcionam que não são somente os peritos que estão envolvidos e tomam decisões sobre as questões sociocientíficas e/ou socioambientais, mas também todos os cidadãos, pois é impossível atingir uma única decisão válida e racional, uma vez que os conflitos de interesses produzem decisões divergentes. Podemos, então, concluir que o essencial para as iniciativas de ativismo sociocientífico e socioambiental terem sucesso nas escolas é dar a oportunidade aos alunos e aos professores de se envolverem em situações concretas de ativismo (FANICA, 2017, p. 16).

Nota-se que Portugal está um pouco mais avançado no que se refere à utilização das CSC, pois, enquanto o Brasil ainda está focado na formação de professores, o país europeu já está centrado nas ações sociopolíticas, as quais correspondem ao objetivo final da inclusão das CSC nas aulas de ciências.

Os níveis de ensino abordados nas teses e dissertações analisadas são apresentados na Figura 2. No caso português, o sistema educacional básico divide-se em Ensino Básico $1^{10}\left(1^{\circ}\right.$ ao $4^{\circ}$ ano), $2^{\circ}$ ( $5^{\circ}$ e $6^{\circ}$ ano) e $3^{\circ}$ ( $7^{\circ}$ ao $9^{\circ}$ ano) ciclo e Ensino Secundário ( $10^{\circ}$ ao $12^{\circ}$ ano). No Brasil, tem-se o Ensino Fundamental I ( $1^{\circ}$ ao $5^{\circ}$ ano) e II ( $6^{\circ}$ ao $9^{\circ}$ ano) e Ensino Médio (1a a $3^{a}$ série). Além disso, no sistema brasileiro existe a Educação para Jovens e Adultos (EJA), para as pessoas que não puderam completar o Ensino Básico na idade ideal.

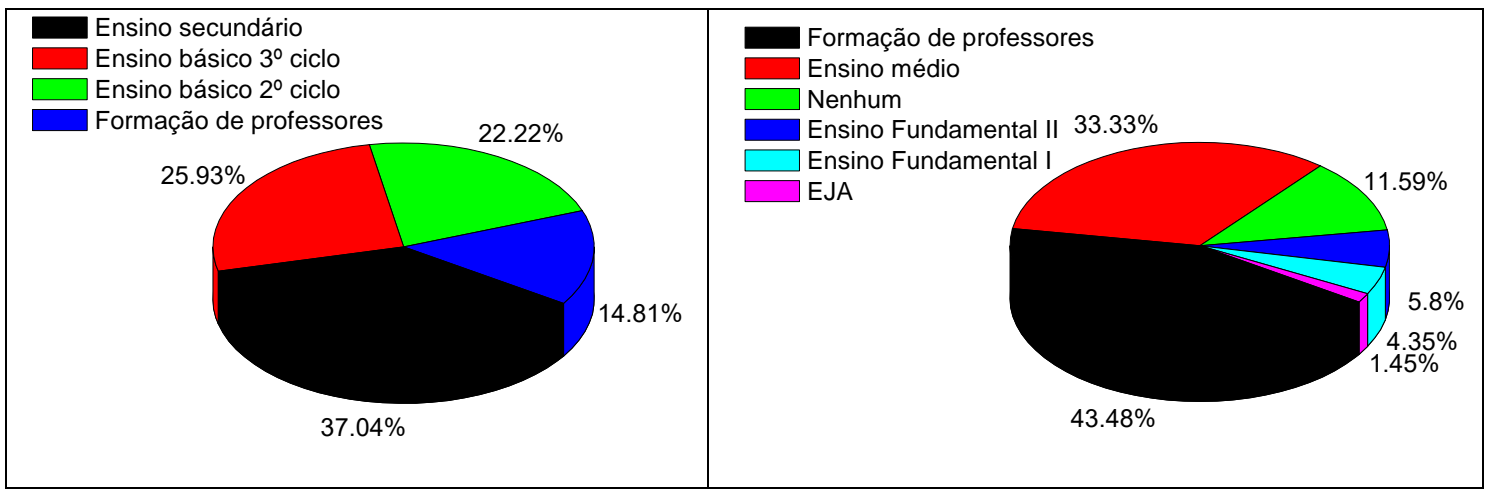

Figura 2 - Níveis de ensino abordados nos trabalhos portugueses (gráfico da esquerda) e brasileiros (gráfico da direita).

Nota-se que a maioria dos trabalhos brasileiros foca na formação de professores, como já verificamos pelas palavras-chave, e em Portugal, este é o nível menos explorado. Os pesquisadores portugueses concentram-se em desenvolver pesquisas que aproximem as CSC do Ensino Básico e Secundário (85,19\%, somando os três níveis que aparecem no gráfico). Já os investigadores brasileiros desenvolveram um número menor de trabalhos 
com esse objetivo (44,93\%, somando os quatro níveis que aparecem no gráfico). Além disso, no Brasil 11,59\% das pesquisas não envolvem nenhum nível educacional, são os trabalhos teóricos e do tipo estado do conhecimento.

Quase metade dos trabalhos portugueses (48,15\%) dedica-se aos alunos do Ensino Básico ( $2^{\circ}$ e $3^{\circ}$ ciclos, apenas o $1^{\circ}$ ciclo não foi abordado). Enquanto apenas 10,15\% das pesquisas brasileiras concentram-se nessa faixa etária (Ensino Fundamental I e II). Zeidler e Nichols (2009) afirmam que a maioria dos docentes acha que, nos anos iniciais da Educação Básica, não existe tempo para realizar atividades de discussão de CSC, pois a matemática e a língua materna devem ser priorizadas. Entretanto, os autores consideram que temas controversos podem ajudar no desenvolvimento da leitura e interpretação de textos. Portanto, é importante existirem pesquisas voltadas para esses anos da Educação Básica. No Brasil, este dado pode ainda ser interpretado em função da formação dos professores, uma vez que em geral, nos cursos de Pedagogia, temas relacionados às ciências ocupam menor espaço nos currículos. Por consequência, sendo os professores oriundos desses cursos que atuam no Ensino Fundamental I e II, acabam tendo maiores dificuldades em abordar temáticas relacionadas às ciências. (SANTOS et al., 2020).

Quadro 2: Tipos de CSC mais frequentes nas teses e dissertações brasileiras e portuguesas.

\begin{tabular}{|c|c|c|c|c|}
\hline \multirow{2}{*}{$\begin{array}{l}\text { Ordem de } \\
\text { frequência }\end{array}$} & \multicolumn{2}{|c|}{ Teses e dissertações portuguesas } & \multicolumn{2}{|c|}{ Teses e dissertações brasileiras } \\
\hline & Tipo de CSC & Quais são & Tipo de CSC & Quais são \\
\hline $1^{a}$ & Ambientais & $\begin{array}{l}\text { Aquecimento global, } \\
\text { aumento do efeito } \\
\text { estufa, degradação da } \\
\text { camada de ozônio, } \\
\text { chuva ácida, resíduos } \\
\text { sólidos, pesticidas, } \\
\text { deflorestação, perda } \\
\text { da biodiversidade, } \\
\text { degelo e erosão, } \\
\text { poluição, plásticos nos } \\
\text { oceanos, mudanças } \\
\text { climáticas }\end{array}$ & Ambientais & $\begin{array}{c}\text { Agrotóxicos, } \\
\text { aquecimento global, } \\
\text { poluição da água, } \\
\text { mudanças climáticas, } \\
\text { agroecologia, poluição } \\
\text { atmosférica, } \\
\text { desmatamento }\end{array}$ \\
\hline $2^{a}$ & $\begin{array}{l}\text { Biotecnologia } \\
\text { e saúde }\end{array}$ & $\begin{array}{l}\text { Genética humana, } \\
\text { vacinar ou não } \\
\text { vacinar, equilíbrio do } \\
\text { corpo humano, a } \\
\text { manutenção da saúde }\end{array}$ & Alimentares & $\begin{array}{c}\text { Feira livre, alimentos } \\
\text { transgênicos, segurança } \\
\text { alimentar, produção de } \\
\text { peixes, produção de } \\
\text { açúcar, horta, educação } \\
\text { alimentar. }\end{array}$ \\
\hline $3^{\circ}$ & Sociais & $\begin{array}{l}\text { Ocupação antrópica, } \\
\text { educação rodoviária }\end{array}$ & $\begin{array}{l}\text { Biotecnologia } \\
\text { e saúde }\end{array}$ & $\begin{array}{c}\text { Células-tronco, aborto, } \\
\text { medicamentos, células } \\
\text { sintéticas, alterações } \\
\text { genéticas, clonagem, } \\
\text { fosfoetanolamina }\end{array}$ \\
\hline
\end{tabular}

Quanto aos tipos de CSC, o Quadro 2 mostra os três mais frequentes nas teses e dissertações brasileiras e portuguesas. É importante frisar que as CSC são situações 
múltiplas, que envolvem todo tipo de aspecto, como sociais, econômicos, ambientais, políticos, etc., e todas as facetas de uma CSC podem ser discutidas. Portanto, a divisão em tipos de CSC feita no Quadro 2 é apenas uma forma de organizar os assuntos e facilitar o entendimento do que é discutido nas pesquisas brasileiras e portuguesas e não uma tentativa de limitar as discussões que podem ser feitas de um assunto.

Notam-se aproximações entre Brasil e Portugal, sendo que os dois países abordam com maior frequência as CSC ambientais e de biotecnologia e saúde. Tal fato pode estar relacionado com a constante presença desses assuntos na mídia. Assim, a informação disponível é grande, facilitando a discussão dos temas nas aulas de ciências. Além disso, as CSC são bastante interdisciplinares, permitindo que sejam trabalhadas em várias disciplinas. Também são temáticas que estão presentes no cotidiano dos alunos e que chamam a atenção dos mesmos, em especial, as de biotecnologia. Este dado vai ao encontro da literatura (HILÁRIO; REIS, 2009), que recomenda fortemente que sejam trabalhadas temáticas próximas ao cotidiano dos alunos, uma vez que essas terão certamente mais aderência e suscitarão maior interesse por parte destes.

Os focos temáticos das teses e dissertações analisadas são apresentados no Quadro 3:

Quadro 3 - Foco temático das teses e dissertações brasileiras e portuguesas.

\begin{tabular}{|c|c|c|c|}
\hline Foco temático & Descrição & $\begin{array}{c}\text { Quantidade } \\
\text { Brasil }\end{array}$ & $\begin{array}{c}\text { Quantidade } \\
\text { Portugal }\end{array}$ \\
\hline $\begin{array}{c}\text { Formação de } \\
\text { professores }\end{array}$ & $\begin{array}{l}\text { Apresentam cursos, grupos de estudos, } \\
\text { grupos de pesquisa, disciplinas ou } \\
\text { atividades isoladas de formação inicial ou } \\
\text { continuada de professores }\end{array}$ & $43,5 \%$ & $16,0 \%$ \\
\hline $\begin{array}{l}\text { Estratégias didáticas } \\
\text { na Educação Básica }\end{array}$ & $\begin{array}{l}\text { Apresentam sequências didáticas ou } \\
\text { atividades isoladas de abordagem } \\
\text { explícita de CSC na Educação Básica }\end{array}$ & $40,6 \%$ & $84,0 \%$ \\
\hline $\begin{array}{l}\text { Projetos de relação } \\
\text { escola/comunidade }\end{array}$ & $\begin{array}{l}\text { Apresentam propostas de projetos } \\
\text { envolvendo CSC que podem ser } \\
\text { realizados em escolas ou na comunidade }\end{array}$ & $7,2 \%$ & $0 \%$ \\
\hline Pesquisas teóricas & $\begin{array}{c}\text { Apresentam discussões teóricas sobre uso } \\
\text { de CSC, vantagens e desvantagens } \\
\text { educativas, desenvolvimento de } \\
\text { habilidades, entre outros }\end{array}$ & $5,8 \%$ & $0 \%$ \\
\hline Análise de material & $\begin{array}{c}\text { Apresentam considerações sobre } \\
\text { currículos, livros, materiais didáticos e } \\
\text { avaliações de larga escala }\end{array}$ & $2,9 \%$ & $0 \%$ \\
\hline
\end{tabular}

Nota-se que pesquisas teóricas, de análise de materiais (como currículos, avaliações e livros didáticos) e projetos de relação escola/comunidade acontecem apenas no Brasil, mesmo que em pequena quantidade. Ou seja, as investigações brasileiras são mais diversificadas. Os pesquisadores portugueses estão quase completamente focados em desenvolver estratégias de ensino para incluir as CSC na Educação Básica. Conforme já foi apontado, no Brasil, a maioria das pesquisas concentra-se na formação de professores, sendo investigados grupos de estudo e pesquisa, disciplinas com licenciandos e cursos de 
formação com docentes já atuantes. O objetivo é sempre preparar os educadores para inserir as CSC em suas aulas. Em Portugal, a maioria das pesquisas se concentra em estratégias didáticas, sendo investigadas sequências didáticas e atividades variadas de abordagem CSC.

Conforme também já apontamos com outros dados, fica cada vez mais evidente que os interesses de pesquisas no Brasil e em Portugal se diferenciam bastante. Uma vez que, mesmo as pesquisas que têm como foco temático as estratégias didáticas na Educação Básica são diferentes nos dois países. A maioria das pesquisas do país europeu apresenta sequências didáticas ou atividades que envolvem a discussão de CSC e, muitas vezes, ações sociopolíticas acerca das temáticas estudadas. Ou seja, os alunos são estimulados a refletir e discutir assuntos controversos do seu cotidiano e agir para tentar resolvê-los. Portanto, existe uma tentativa de usar as CSC para desenvolver competências para a cidadania, como argumentação e tomada de decisão fundamentada. Ou seja, este é um objetivo explícito dos educadores e pesquisadores portugueses, conforme argumenta Marques (2013):

[...] reclama-se da escola um papel no fomento do desenvolvimento de competências de observação da vida, de análise crítica e de intervenção. É necessário que a escola crie situações que permitam aos alunos desenvolverem competências de pesquisa e de organização da informação, estabelecerem relações entre os conteúdos tendo em vista a aquisição de um saber integrado, e desenvolverem competências de vivência numa sociedade que se rege por princípios de uma democracia participativa (MARQUES, 2013, p. 28).

Já as sequências didáticas e atividades de ensino brasileiras que usam a discussão de CSC, têm como objetivo, na maioria dos casos, o ensino dos conteúdos científicos. O desenvolvimento de competências para a cidadania também aparece nos estudos brasileiros, mas é menos frequente e menos destacado do que nas pesquisas portuguesas. Portanto, as CSC são utilizadas de forma diferente no ensino dos dois países. Ou seja, lá visando ação, atuação crítica e cidadã, aqui visando compreensão de conteúdos. Certamente que um objetivo não exclui o outro, todavia, a justificativa principal do trabalho com as CSC nas aulas de ciências é justamente o que é desenvolvido em Portugal.

E, finalmente, a última categoria analisada nesta investigação, diz respeito à natureza da ciência, a qual vem sendo bastante pesquisa no Brasil (KRUPCZAK; AIRES, 2018). Como já mencionado anteriormente, as CSC podem ser usadas para levar os alunos a ter uma melhor compreensão sobre a natureza da ciência. Por isso, foram analisadas quais pesquisas tinham, entre seus objetivos gerais e específicos, algo voltado para a discussão dos aspectos da construção do conhecimento científico e do funcionamento da ciência. Encontrou-se apenas uma tese portuguesa (4,2\%) e quatro pesquisas brasileiras (5,8\%) que usaram as CSC para, de alguma forma, abordar a natureza da ciência. Ou seja, são raros os investigadores que usam temas controversos como estratégia didática para discutir os aspectos da atividade científica.

A tese portuguesa teve como objetivo entender quais as compreensões e reações de professores e alunos às CSC veiculadas pela mídia. Primeiramente, foram realizados questionários, entrevistas e observações para identificar as concepções de CSC e da 
natureza da ciência de alunos e professores. Os resultados mostraram que eles apresentavam visões deformadas ${ }^{7}$ sobre a ciência e os cientistas. Posteriormente, foi desenvolvida uma formação com os docentes, a qual demonstrou a potencialidade da discussão de CSC para a abordagem sobre a natureza da ciência.

Em relação às dissertações e teses brasileiras, uma delas tem como um dos objetivos entender como a discussão de CSC pode ser usada para debater a natureza da ciência, realizando um grupo de pesquisa com professores. O autor usou questões problema para iniciar as discussões sobre os aspectos da natureza da ciência. Por fim, o pesquisador concluiu que a abordagem ajudou os docentes a entender melhor a construção do conhecimento científico e sobre como incluir tais reflexões em suas aulas.

Outra dissertação teve como objetivo entender como as CSC podem contribuir para o desenvolvimento de visões adequadas de ciência em alunos de Ensino Médio. Foi desenvolvida e aplicada uma sequência didática sobre alimentos transgênicos. A autora concluiu que "[...] a abordagem integrada e explícita de NC [Natureza da Ciência] e argumentação em contexto sociocientífico favoreceu o desenvolvimento de uma visão ampla sobre a ciência nos estudantes investigados" (MARTINS, 2016, p. 147), porque os alunos apresentaram entendimentos mais adequados da atividade científica, quando comparados com os apresentados inicialmente.

Em relação às teses, uma objetivou entender como a população compreende a ciência e a tecnologia envolvida na produção de medicamentos. A autora encontrou que, independentemente do nível de escolaridade, as pessoas têm visões simplistas sobre natureza da ciência, as quais, segundo a pesquisadora, são transmitidas pela mídia e pelo Ensino de Ciências.

A última tese brasileira que tinha entre seus objetivos a discussão da natureza da ciência no contexto das CSC, objetivou identificar como a discussão de uma CSC pode contribuir para o desenvolvimento de compreensões adequadas sobre natureza da ciência em licenciandos de vários cursos. A autora desenvolveu uma disciplina optativa com estudantes de diferentes cursos de licenciatura. No início da matéria, os alunos demonstraram ter visões simplificadas da atividade científica. Ao final da disciplina, as concepções dos licenciandos mudaram, indo ao encontro de uma visão mais próxima de como a ciência é construída.

Portanto, estes cinco trabalhos demonstram que as CSC podem ser utilizadas para discutir aspectos sobre natureza da ciência de forma contextualizada, ajudando docentes e estudantes a desenvolver visões mais adequadas de ciência, independentemente do país em que as pesquisas foram realizadas.

\section{Conclusões}

O objetivo deste artigo foi analisar como as CSC são abordadas nas pesquisas brasileiras e portuguesas, buscando identificar as semelhanças e diferenças dos dois contextos educacionais e de pesquisa. Consideramos tê-lo atingido, uma vez que conseguimos identificar os aspectos que nos propomos a investigar.

\footnotetext{
${ }^{7}$ Esta é uma categoria de Pérez et. al. (2001).
} 
Como semelhanças, verifica-se que os pesquisadores dos dois países consideram que a discussão de CSC pode facilitar o desenvolvimento da alfabetização científica. Também observamos que em ambos os casos, faltam estudos teóricos, o que é preocupante, pois é fundamental que existam pesquisadores que analisem os fatores envolvidos na discussão de CSC, construindo teorias que auxiliem os docentes e outros pesquisadores a tomar decisões e desenvolver atividades de sala de aula conscientes e fundamentadas. Caso contrário, as ações práticas tornam-se sem sentido, não ajudando os alunos a desenvolver novas capacidades e habilidades. Outra semelhança entre as pesquisas é o fato de que a natureza da ciência é pouco explorada (em torno de $5 \%$ dos estudos dos dois países). Possivelmente, a relação entre as CSC e a natureza da ciência ainda não é muito discutida nas teses e dissertações porque é uma questão relativamente recente na literatura mundial.

Em relação às diferenças, estas podem ser notadas, principalmente, no foco temático das pesquisas. No Brasil, o ponto central é a formação de professores, enquanto que em Portugal são as estratégias didáticas para a Educação Básica. Isso pode significar que os cursos de licenciatura e pedagogia portugueses já abordam as CSC e, portanto, os docentes já estão preparados para discutir tais assuntos em suas aulas. Com isso, os pesquisadores não precisam focar tanto na formação de professores e podem realizar mais pesquisas centradas no processo de ensino e aprendizagem.

Outra diferença está nas sequências e atividades didáticas que são realizadas nos dois países. Os trabalhos portugueses que apresentam este tipo de pesquisa concentram-se, na maioria dos casos, no desenvolvimento de competências para a cidadania e para o ativismo. Já os estudos brasileiros focam, principalmente, na aprendizagem dos conteúdos científicos. Tal fato pode estar relacionado com a menor qualidade da Educação Básica brasileira, quando comparada com a portuguesa, por vários motivos, desde as lacunas na formação dos professores que atuam neste nível de ensino, passando pelos currículos dos cursos de Pedagogia, que dão pouca ênfase às ciências, até a pouca valorização da profissão docente. Os reflexos dos problemas apontados, os quais se evidenciaram nos dados analisados, podem ser também observados em avaliações de larga escala, como, por exemplo, nas pesquisas do Programa Internacional de Avaliação de Estudantes (Pisa) de 2018, em que "[...] Portugal pontuou em torno da média da OCDE em leitura, matemática e ciências [...]. Quando avaliado por um período mais longo, Portugal é um dos poucos países com uma trajetória positiva de melhoria nos três assuntos" (OCDE, 2020a, p. 1, tradução nossa). Já "[...] os estudantes no Brasil pontuaram abaixo da média da OCDE em leitura, matemática e ciências. Apenas 2\% dos alunos tiveram os níveis mais altos de proficiência (Nível 5 ou 6) em pelo menos uma disciplina (média da OCDE: 16\%) e 43\% dos alunos obtiveram pontuação abaixo do nível mínimo de proficiência (Nível 2) nos três sujeitos (média da OCDE: 13\%)" (OCDE, 2020b, p. 1, tradução nossa). A média do Brasil em ciências foi de 404 e de Portugal foi de 492, uma diferença grande. Por isso a importância de continuar a investir na formação dos professores brasileiros para que, a médio prazo, estes consigam utilizar estratégias didáticas, como as CSC, atingindo, dessa maneira, a formação de cidadãos críticos, que consigam atuar na sociedade e não apenas reproduzam conceitos vazios, que não o auxiliem na leitura do mundo onde vivem. 


\section{Referências}

ALMEIDA, P.; CÉSAR, M. Contributos da interacção entre pares, em aulas de ciências, para o desenvolvimento de competências de argumentação. Interacções, n. 6, p. 163-196, 2007.

ALMEIDA, M. T.; GUIMARÃES, M. A. Raciocínio moral em questões sociocientíficas: argumentação de licenciados de ciências sobre a eutanásia. Amazônia: Revista de Educação em Ciências e Matemáticas, v. 15, n. 34, p. 80-95, jul./dez. 2019.

AULER, D.; DELIZOICOV, D. Alfabetização científico-tecnológica para quê? Revista Ensaio, v. 3, n. 1, p. 122-134, jul./dez. 2001.

CENTRO DE GESTÃo E ESTUdOS eStRAtÉGICOS (CGEE). Percepção pública de C\&T no Brasil: resumo executivo. Brasília, 2019. Disponível em: https://www.cgee.org.br/documents/10195/734063/CGEE_resumoexecutivo_Percepc ao_pub_CT.pdf. Acesso em: 8 abril 2020.

COSTA, B. C. C. Abordagem investigativa e questões sociocientíficas como proposta de alfabetização científica no ensino de biologia. 2018. 151 f. Dissertação (Mestrado em Ensino de Ciências Naturais e Matemática) - Universidade Federal do Rio Grande do Norte, Natal, 2018.

ESPÍRITO SANTO, M.; REIS, P. Utilização de Blogues na discussão de controvérsias sociocientíficas na disciplina de Ciências da natureza. Caderno Pedagógico, v. 10, n. 1, p. 924, 2013.

FANICA, J. F. C. Potencialidades das redes sociais na promoção de ativismo fundamentado sobre problemáticas sociais de base científica e tecnológica. 2017. 349 f. Tese (Doutorado em Educação) - Instituto de Educação, Universidade de Lisboa, Lisboa, 2017.

GALVÃO, C.; REIS, P.; FREIRE, S. A discussão de controvérsias sociocientíficas na formação de professores. Ciência \& Educação, v. 17, n. 3, p. 505-522, 2011.

PÉREZ, D. G.; MONTORO, I. F.; ALIS, J. C.; CACHAPUZ, A.; PRAIA, J. Para uma imagem não deformada do trabalho científico. Ciência \& Educação, v. 7, n. 2, p. 125-153, 2001.

HILÁRIO, T.; REIS, P. R. Potencialidades e limitações de sessões de discussão de controvérsias sociocientíficas como contributos para a literacia científica. Revista de Estudos Universitários, v. 35, n. 2, p. 167-183, 2009.

HOLBROOK, J.; RANNIKMAE, M. The meaning of Scientific Literacy. International Journal of Environmental \& Science Education, v. 4, n. 3, p. 275-288, 2009.

HURD, P. Scientific literacy: new minds for a changing world. Science Education, v. 82, n. 3, p. 407-416, 1998.

KOLSTO, S. D. Scientific Literacy for Citizenship: Tools for Dealing with the Science Dimension of Controversial Socioscientific Issues. Science Education, v. 85, p. 291-310, 2001.

KARISAN, D.; ZEIDLER, D. L. Contextualization of Nature of Science within the Socioscientific Issues Framework: A Review of Research. International Journal of Education in Mathematics, Science and Technology, v. 5, n. 2, p. 139-152, 2017. 
KRUPCZAK, C.; AIRES, J. A. Natureza da ciência: o que os pesquisadores brasileiros discutem? Amazônia: Revista de Educação em Ciências e Matemáticas, v. 14, n. 32, p. 19-32, 2018.

KRUPCZAK, C.; AIRES, J. A. Controvérsias sociocientíficas: uma análise da produção acadêmica brasileira. Vidya, v. 39, p. 277-299, 2019.

KRUPCZAK, C.; LORENZETTI, L.; AIRES, J. A. Controvérsias sociocientíficas como forma de promover os eixos da alfabetização científica. Tear: Revista de Educação, Ciência e Tecnologia, v. 9, n. 1, p. 1-20, 2020.

LEDERMAN, N. G.; ANTINK, A.; BARTOS, S. Nature of science, scientific inquiry, and socioscientific issues arising from genetics: A pathway to developing a scientifically literate citizenry. Science \& Education, v. 23, n. 2, p. 285-302, 2014.

LEITE, R. F.; RODRIGUES, M. A. Aspectos sociocientíficos e a questão ambiental: uma dimensão da alfabetização científica na formação de professores de química. Revista de Ensino de Ciências e Matemática, v. 9, n. 3, p. 38-53, 2018.

LOPES, W. Z.; GARCIA, R. N. Abordagem dos temas alfabetização científica (AC) e ciência, tecnologia, sociedade (CTS). Revista Eletrônica Científica Ensino Interdisciplinar, v. 5, n. 14, p. 283-301, 2019.

LUDKE, M.; ANDRÉ, M. E. D. A. Pesquisa em educação: abordagens qualitativas. Rio de Janeiro: E.P.U, 2013.

MARTINS, M. R. Ensino Explicito e Integrado de Natureza da Ciência e Argumentação em um Contexto Sociocientífico para Estudos de Química do Ensino Médio. 174 f. Dissertação (Mestrado em Educação) - Universidade Federal de Minas Gerais, Belo Horizonte, 2016.

MARQUES, A. R. L. As potencialidades de uma abordagem interdisciplinar entre as ciências naturais e as tecnologias de informação e comunicação no desenvolvimento de um projeto de ativismo ambiental. 2013. 209 f. Dissertação (Mestrado em Ensino de Biologia e de Geologia) - Instituto de Educação, Universidade de Lisboa, Lisboa, 2013.

MOURA, B. A. O que é natureza da Ciência e qual sua relação com a História e Filosofia da Ciência? Revista Brasileira de História da Ciência, Rio de Janeiro, v. 7, n. 1, p. 32-46, jan/jun 2014.

PRAIA, J.; PÉREZ, D. G.; VILCHES, A. O papel da natureza da Ciência na educação para a cidadania. Ciência \& Educação, v. 13, n. 2, p. 141-156, 2007.

REIS, P. Acción socio-política sobre cuestiones socio-científicas: reconstruyendo la formación docente y el currículo. Uni-pluri/versidad, v. 14, n. 2, p. 16-26, 2014.

REIS, P. R. Ciência e Controvérsia. Revista de Estudos Universitários, v. 35, n. 2, p. 9-15, 2009.

REIS, P. A Promoção do Pensamento através da Discussão dos Novos Avanços na Área da Biotecnologia e da Genética. 1997. 202 f. Dissertação (Mestrado em Educação) Universidade de Lisboa, Departamento de Educação da Faculdade de Ciências, Lisboa, 1997.

REIS, P. G. R.; TINOCA, L. A. F. A avaliação do impacto do projeto "We Act" nas percepções dos alunos acerca das suas competências de ação sociopolítica. Revista Brasileira de Ensino de Ciência e Tecnologia, v. 11, n. 2, p. 214-231, 2018. Disponível em: https://periodicos. utfpr.edu.br/rbect/article/view/8435. 
ORGANIZATION FOR ECONOMIC CO-OPERATION AND DEVELOPMENT (OECD). Programme for International Student Assessment (PISA) results from PISA 2018 - Portugal. Disponivel em: https://www.oecd.org/pisa/publications/PISA2018_CN_PRT.pdf. Acesso em: 7 abril 2020a.

ORGANIZATION FOR ECONOMIC CO-OPERATION AND DEVELOPMENT (OECD). Programme for International Student Assessment (PISA) results from PISA 2018 - Brasil. Disponível em: https://www.oecd.org/pisa/publications/PISA2018_CN_BRA.pdf. Acesso em: 7 abril 2020b.

ROMANOWSKI, J. P.; ENS, R. T. As pesquisas denominadas do tipo "estado da arte" em educação. Revista Diálogo Educacional, v. 6, n. 19, p. 37-50, set./dez. 2006.

SADLER, T. D. Informal reasoning regarding socioscientific issues: a critical review of research. Journal of Research in Science Teaching, v. 41, n. 5, p. 513-536, 2004.

SADLER, T. D.; ZEIDLER, D. L. The morality of socioscientific issues: construal and resolution of genetic engineering dilemmas. Science Education, v. 88, n. 1, p. 4-27, 2004.

SANTOS, D. C.; TERESKI, L.; SOARES, D. P.; MARQUES, F. A.; AIRES, J. Experimentação problematizadora: análise de uma proposta para formação continuada de professores da educação básica. Revista Brasileira de Educação em Ciências e Educação Matemática, v. 4, n. 1, p. 81-100, 2020.

SASSERON, L. H.; CARVALHO, A. M. P. de; Alfabetização científica: uma revisão bibliográfica. Investigações em Ensino de Ciências, v. 16, n. 1, p. 59-77, 2011.

SCHEID, N. M. J.; REIS, P. As tecnologias da informação e da comunicação e a promoção da discussão e ação sociopolítica em aulas de Ciências naturais em contexto português. Ciência \& Educação, v. 22, n. 1, p. 129-144, 2016.

ZEIDLER, D. L.; NICHOLS, B. H. Socioscientific issues: theory and practice. Journal of Elementary Science Education, v. 21, n. 2, p. 49-58, 2009. 